\title{
EFFECT OF CURING TIME ON TOP TO BOTTOM MICROHARDNESS OF BULK-FILL COMPOSITE
}

\author{
Amr Mohamed Marzouk* , Hanan Abdel Aziz Niazi**, \\ Mohammed Nasser Mohammed ${ }^{* * *}$ and Rasha Hassan Afifi* ${ }^{* *}$
}

\begin{abstract}
Objectives: The aim of this study was to determine the effect of light curing time on top to bottom microhardness of bulk-fill resin composites. Materials and Method: Three bulk-fill resin composites were used Admira fusion x-tra (voco), Tetric Evoceram bulk-fill (Ivoclar vivadent) and Filtek bulk-fill (3M ESPE). Sixty composite specimens were prepared in cylindrical shape. Teflon molds $(4 \mathrm{~mm} \times 4 \mathrm{~mm})$ diameter that are open at the top and the bottom sides were used to prepare the specimens. Thirty specimens were cured according to manufacturers' instructions and the other thirty were cured for 40 seconds using EliparTM light curing unit. All the specimens were cured at $0 \mathrm{~mm}$ distance. After curing process, the specimens were stored at $37^{\circ} \mathrm{C}$ at $100 \%$ humidity for 24 hours. Surface microhardness was measured and data presented as means and standard deviations (SD). Multivariant ANOVA was used to study the effect of different curing time on top and bottom values of microhardness. One-way ANOVA was also used to study the effect of different curing time on top/bottom ratio of microhardness. Results: Curing time showed a non-statistically significant effect on top and bottom mean values of microhardness of bulk-fill composite at $\mathrm{P}>0.05$. However, curing time showed a statistically significant increase on top to bottom microhardness mean ratio of all the materials $P \leq 0.05$. Conclusion: Under the limitations of this study, it can be concluded that, the increase in the light curing time increased the top to bottom microhardness of bulk-fill materials.
\end{abstract}

KEYWORDS: Bulk-fill, microhardness, curing time

\section{INTRODUCTION}

Resin composites are the most commonly used esthetic restorative materials, so manufacturers have always to improve them in terms of the chemical composition and filler reinforcements. Dental composite restorations have a major drawback regarding the degree of cure, which is proportional to the amount of light they are exposed. So, they polymerize to a certain depth which varies with the penetration of a light beam in the bulk material. Recently, many clinicians have shown the preference for time saving restorative procedures for posterior resin applications. A new category of resin composites, a bulk-fill resin composite, has been introduced

\footnotetext{
* Assistant lecturer, Conservative Dentistry Department, Faculty of Dentistry, Future University in Egypt.

**Professor of Operative Dentistry, Faculty of Dentistry, Ain Shams University.

*** Lecturer of Operative Dentistry, Faculty of Dentistry, Ain Shams University

** Lecturer, Conservative Dentistry Department, Faculty of Dentistry, Future University in Egypt.
} 
over the past few years. According to the manufacturers, these materials can be applied in bulks of 4 $\mathrm{mm}$, without necessitating a prolonged curing time, or a light curing unit with increased irradiance.

Substantial surface micro hardness of the restoration is one of the main requirements especially in posterior stress-bearing areas. The physical and the mechanical properties of dental composites are directly influenced by the degree of conversion achieved during polymerization ${ }^{1,2}$. There are many variables that influence the amount of light energy delivered to the top and bottom surfaces of the restoration which may result in inadequate polymerization ${ }^{3}$. Evidence shows that several factors namely the filler type (size and volume), passage of light, thickness, color (shade) of restorative materials, light curing time, distance from the light source to the surface of sample, and light intensity affect the rate and depth of polymerization ${ }^{4}$. According to these controversies, the purpose of this study was to evaluate the effect of light curing time on top to bottom microhardness of three bulk-fill resin-based composites.

\section{MATERIALS AND METHODS}

Three different types of bulk-fill composite materials were used in this study. Materials used in this study, their compositions, manufacturers and batch numbers are listed in (table 1).

\section{Study design:}

A total number of sixty composite cylindrical specimens were prepared. The specimens were equally divided into three groups (20 specimens each) according to the type of bulk-fill resin composite used i.e. Admira fusion x-tra, Tetric EvoCeram and Filtek ${ }^{\mathrm{TM}}$ bulk-fill. Each group was further subdivided into two subgroups (10 specimens each) according to the light curing time either according to manufacturer's instructions (control group) or 40 seconds. Specimens were subjected to top to bottom Vickers microhardness testing.

\section{Specimens preparation}

Sixty standardized disc-shaped resin composite specimens were prepared using specially constructed split Teflon mold with an internal diameter of 4 $\mathrm{mm}$ and thickness of $4 \mathrm{~mm}$. The mold consisted of two parts with an outer metallic ring to assist reassembling of the two parts together. All the specimens were prepared by using a glass slide with overlying celluloid Mylar strip (Gennex Mylar Matrix - Clear Celluloid Strips, Hongkong).The Mylar strip was placed under the mold against which the composite material was packed inside in one increment using plastic instrument (Lustra Plastic Filling Instrument No.4, Dentsply, USA). Another celluloid strip was placed above the mold and a glass slide with a load of $1 \mathrm{~kg}$ was applied for 30 seconds to ensure consistent packing of the specimens.

The load and microscope slide were then removed. All the samples were light cured from the top surface only according to the experimental design, either according to manufacturer instructions (10 seconds for Tetric EvoCeram and 20 seconds for (Admira Fusion X-tra and Filtek ${ }^{\mathrm{TM}}$ bulk fill), or for 40 seconds. This was performed by using high intensity LED light curing unit (EliparTM, 3M ESPE, USA.) with an output $\geq 1200 \mathrm{~mW} / \mathrm{cm}^{2}$ measured by a radiometer (Demetron/Kerr, Danbury, USA). It should be noted that the power density of the light curing unit was checked after curing every 5 specimens using a radiometer and then the samples were removed from the mold, the surface facing the light-curing unit was marked with a small dot using a permanent marker (XQ Marker, Dongapen, Korea). The samples were placed in a light proof vial at $37^{\circ} \mathrm{C}$ for 24 hours at $100 \%$ humidity to prevent ambient light from causing an additional post light-curing polymerization.

\section{Microhardness testing}

Relative microhardness was measured by doing the surface microhardness test on both surfaces of the samples (top and bottom) to give indication about the depth of cure by calculating the ratio of 
bottom/top hardness. A minimum value of 0.80 has to be reached in order to consider the bottom surface. Vickers microhardness tester (Nexus 4000, Innovatest, model no.4503, Netherland) with a Vickers diamond indenter was used by applying 3 indentations at $1 \mathrm{~mm}$ apart on each surface and a load of 50 grams for 10 seconds. The diagonal lengths of the indentations were measures by built in scaled microscope with 20Xobjective lens and the Vickers values were automatically converted into microhardness values. The mean values of the 3 indentations for the 5 samples on each surface were calculated.

\section{Statistical analysis}

Data presented as mean, standard deviation (SD). Microhardness showed a parametric distribution, Multivariant ANOVA used to study the effect of different curing time on top and bottom values of microhardness followed by post-hoc test for pair- wise comparison when ANOVA is significant with Bonferroni correction. One Way ANOVA used to study the effect of different Curing time on top/bottom ratio of microhardness. The significance level was set at $\mathrm{P} \leq 0.05(\alpha=0.05)$. Statistical analysis was performed with IBM ${ }^{\circledR}$ SPSS ${ }^{\circledR}$ (SPSS Inc., IBM Corporation, NY, USA) Statistics Version 25 for Windows.

\section{RESULTS}

Means and standard deviations (SD) for the effect of different curing times on top and bottom microhardness of the tested materials were presented in table (2).For the top surface: Results showed a non statistically significant difference between control and 40 seconds groups on mean microhardness values where for Admira Fusion $x$-tra in the control group is $(70.52 \pm 1.69 \mathrm{VHN})$ and in the 40 seconds group $(71.8 \pm 2.06 \mathrm{VHN})$ at $(\mathrm{P}$ value $=0.787)$, while

TABLE (1): Materials, brand name, composition, manufacturers and batch number

\begin{tabular}{|c|c|c|c|}
\hline Materials & Description & Composition & $\begin{array}{c}\text { Manufacturer and } \\
\text { batch number }\end{array}$ \\
\hline $\begin{array}{l}\text { Admira } \\
\text { fusion } x \text {-tra }\end{array}$ & $\begin{array}{l}\text { Ormocer based light cured } \\
\text { bulk fill composite. } \\
\text { Universal shade }\end{array}$ & $\begin{array}{l}\text { Nanohybrid, organically modified ceramics' } \\
\text { technology (ORMOCER } ®) \text { silicon oxide matrix } \\
\text { and silicon oxide fillers. } \\
\text { Filler content of } 84 \% \text { by weight, no monomers. }\end{array}$ & $\begin{array}{l}\text { VOCO } \\
\text { Cuxhaven. } \\
\text { Germany } \\
\text { Lot } 1511105\end{array}$ \\
\hline $\begin{array}{l}\text { Tetric } \\
\text { EvoCeram } \\
\text { Bulk fill } \\
\text { [TE] }\end{array}$ & $\begin{array}{l}\text { Lacerin based light cured } \\
\text { bulkfill composite } \\
\text { IVA shade. }\end{array}$ & $\begin{array}{l}\text { Bis-GMA, UDMA,Ba-Al-Si-glass, pre-polymer } \\
\text { filler (monomer, glass filler and ytterbium } \\
\text { fluoride), spherical mixed oxide. } \\
\text { Filler content } 79-81 \% \text { by weight (including } 17 \% \\
\text { pre-polymers)/60-61\% by volume. }\end{array}$ & $\begin{array}{l}\text { Ivoclar Vivadent, } \\
\text { Schaan, } \\
\text { Liechtenstein } \\
\text { Lot v02758. }\end{array}$ \\
\hline $\begin{array}{l}\text { Filtek }^{\mathrm{TM}} \\
\text { bulk fill }\end{array}$ & $\begin{array}{l}\text { Nano hybrid light cured } \\
\text { bulkfill composite } \\
\text { A2 shade. }\end{array}$ & $\begin{array}{l}\text { Fillers are combination of agglomerated/ } \\
\text { nonaggregated20nmsilicafiller, a non- } \\
\text { agglomerated/non-aggregated } 4 \text { to } 11 \mathrm{~nm} \text { zirconia } \\
\text { filler, an aggregated zirconia/silica cluster filler } \\
\text { (comprised of } 20 \mathrm{~nm} \text { silica and } 4 \text { to } 11 \mathrm{~nm} \\
\text { zirconia particles) and a ytterbium trifluoride filler } \\
\text { consisting of agglomerate } 100 \mathrm{n} \text { particles. } \\
\text { The inorganic filler loading is about } 76.5 \% \text { by } \\
\text { weight ( } 58.4 \% \text { by volume) contains AUDMA, } \\
\text { UDMA and } 1,12 \text {-dodecane-DMA. }\end{array}$ & $\begin{array}{l}\text { 3M ESPE, St } \\
\text { Paul MN, } \\
\text { USA } \\
\text { Lot N753785. }\end{array}$ \\
\hline
\end{tabular}


for Filtek $^{\mathrm{TM}}$ Bulk-Fill in the control group it was $(71.52 \pm 10.38 \mathrm{VHN})$ and in the 40 seconds it was $(72.10 \pm 3.89 \mathrm{VHN})$ at $(\mathrm{P}$ value $=0.813)$ and Tetric EvoCeram ${ }^{\circledR}$ in the control group $(58.89 \pm 1.81 \mathrm{VHN})$ and in the 40 seconds $(59.21 \pm 1.18 \mathrm{VHN})$ at $(\mathrm{P}$ value $=0.896$ ).

For the bottom surface: Results showed a non statistically significant difference between control and 40 seconds groups on mean microhardness, where Admira Fusion $x$-tra in the control group $(69.14 \pm 0.73$ $\mathrm{VHN})$ and in the 40 seconds group $(65.46 \pm 2.32 \mathrm{VHN})$ at $(\mathrm{P}$ value $=0.079)$ and Filtek ${ }^{\mathrm{TM}}$ Bulk-Fill in the control group $(67.10 \pm 4.67 \mathrm{VHN})$ and in the 40 seconds group $(66.22 \pm 4.86 \mathrm{VHN})$ at $(\mathrm{P}$ value $=0.670)$ except Tetric EvoCeram ${ }^{\circledR}$ which showed a statistically significant increase in microhardness mean values in the control groups $(49.79 \pm 1.61 \mathrm{VHN})$ and in the 40 seconds $(55.23 \pm 1.13 \mathrm{VHN})$ at $(\mathrm{p}$ value $=0.011)$.

Means and standard deviations (SD) for Top/ Bottom microhardness ratio for different curing times were presented in table (3). Materials showed a statistically significant increase on top to bottom microhardness mean ratio at ( $\mathrm{P}$ value $\leq 0.05$ ). Where Admira Fusion x-tra was $(0.92 \pm 0.05)$ for the control group and $(0.98 \pm 0.02)$ for 40 seconds group, and Tetric EvoCeram ${ }^{\circledR}$ was $\left.0.84 \pm 0.04\right)$ ) for the control group and $(0.94 \pm 0.03)$ for the 40 seconds group. Filtek $^{\mathrm{TM}}$ Bulk-Fill was the only material that showed no statistically significant difference between the control and 40 seconds group at ( $\mathrm{p}$ value $=0.337$ ).

TABLE (2) Mean and standard deviation (SD) for the effect of curing time on top and bottom microhardness of the tested materials:

\begin{tabular}{|c|c|c|c|c|c|c|}
\hline & & \multicolumn{2}{|c|}{ Control } & \multicolumn{2}{|c|}{40 Sec. } & \multirow{2}{*}{ p-value } \\
\hline & & Mean & SD & Mean & SD & \\
\hline \multirow[t]{3}{*}{ Top } & Admira Fusion $\mathrm{x}$-tra & 70.52 & \pm 1.69 & 71.18 & \pm 2.06 & $0.787 \mathrm{NS}$ \\
\hline & Filtek $^{\mathrm{TM}}$ Bukl-Fill & 71.52 & \pm 10.38 & 72.10 & \pm 3.89 & $0.813 \mathrm{NS}$ \\
\hline & Tetric EvoCeram ${ }^{\circledR}$ & 58.89 & \pm 1.81 & 59.21 & \pm 1.18 & $0.896 \mathrm{NS}$ \\
\hline \multirow[t]{3}{*}{ Bottom } & Admira Fusion $\mathrm{x}$-tra & 69.14 & \pm 0.73 & 65.46 & \pm 2.32 & $0.079 \mathrm{NS}$ \\
\hline & Filtek $^{\mathrm{TM}}$ Bulk-Fill & 67.10 & \pm 4.67 & 66.22 & \pm 4.86 & $0.670 \mathrm{NS}$ \\
\hline & Tetric EvoCeram $®$ & 49.79 & \pm 1.61 & 55.23 & \pm 1.13 & $0.011^{*}$ \\
\hline
\end{tabular}

$*=$ Significant at $p \leq 0.05$,

NS=Non-significant

TABLE (3) Mean and standard deviation (SD) for the effect of different curing times on top to bottom microhardness ratio of the tested materials :

\begin{tabular}{|c|c|c|c|c|c|c|c|}
\hline & & & \multicolumn{2}{|c|}{ Control } & \multicolumn{2}{|c|}{40 Sec. } & \multirow{2}{*}{ p-value } \\
\hline & & & Mean & SD & Mean & SD & \\
\hline \multirow{3}{*}{$\begin{array}{c}\text { Top/ } \\
\text { Bottom }\end{array}$} & \multirow{3}{*}{$0 \mathrm{~mm}$} & Admira Fusion $\mathrm{x}$-tra & 0.92 & \pm 0.05 & 0.98 & \pm 0.02 & $0.043 *$ \\
\hline & & Filtek $^{\mathrm{TM}}$ Bulk-Fill & 0.92 & \pm 0.08 & 0.95 & \pm 0.04 & $0.337 \mathrm{NS}$ \\
\hline & & Tetric EvoCeram® & 0.84 & \pm 0.04 & 0.94 & \pm 0.03 & $0.002 *$ \\
\hline
\end{tabular}




\section{DISCUSSION}

Selection of bulk-fill materials (BFMs) was done because of possible decrease in the intensity of the light transmitting through the material. The main concern with these BFMs is to ensure sufficient polymerization at the deeper portions and the bottom by receiving enough light energy. Since bulk filling itself increases light path length into the deep subsurface and resin volume by the increased cavity depth and each BFCs adopt different strategies for achieving high light transmission and flow ability, their complex effects on hardness, polymerization shrinkage, and color may have different trend compared to those of general RBCs. ${ }^{5}$ So, in this study we investigated the effect of increasing the curing time on the microhardness of the bulk-fill materials.

Selection of Tetric Evoceram bulk-fill was due to the presence of polymerization booster (Ivocerin) which is a highly reactive photo-initiator system that allows a faster, deeper curing than other composites up to $4 \mathrm{~mm}$ and light sensitivity inhibitor that acts as a protective shield against ambient light like operating light ${ }^{6}$. Additionally, the shape of Tetric EvoCeram Bulk-Fill fillers is approaching round-shaped fillers, which were shown to positively influence the translucency ${ }^{7}$. Selection of Admira Fusion X-tra was done as it contains no classic monomers, such as BisGMA, TEGDMA or HEMA, thus eliminating the potential for such substances to be released after polymerization. The ORMOCER $®$ (Organically Modified Ceramics) which have been used in place of conventional monomers consist of large and precondensed molecules of an inorganic matrix with a high degree of cross-linking. With this ORMOCER ${ }^{\circledR}$ technology the overall results on Admira Fusion is one of "excellent biocompatibility" also contains high filler loading $84 \%$ by weight which increases its microhardness. ${ }^{8}$ Filtek $^{\mathrm{TM}}$ Bulk-fill composite was selected as this material has been formulated to be more translucent for blue light by reducing the filler amount. This material also contains additional zirconia fillers. A partial substitution of particulate glass fillers with zirconia/ silica fillers (2.5 and 5.0 wt \%) was found to enhance mechanical properties. ${ }^{9}$

Mylar strips were used to produce a flat and smooth surface and to minimize the formation of the oxygen-inhibition layer during sample preparation. However, this layer is not completely preventable during sample preparation and is unavoidable clinically. In this study, Mylar strips were used to make smooth surface for the ease of indentation measurement and to avoid the need for polishing. This was confirmed during the training on Vickers Hardness tester. Polishing of the sample surfaces has been done in several of the earlier studies ${ }^{10,11}$. However, in this study, the surfaces were not polished before testing. This was for several reasons. In the earlier studies, the aims of polishing were to produce a smooth surface and to remove the oxygen- inhibition layer. The latter has been shown to affect the reading of FTIR and micro- Raman when measuring the DC. As to the effect of polishing on VH measurements, it was reported that polishing sample surface will result in a higher $\mathrm{VH}$ value. ${ }^{12}$

The light curing was performed at $0 \mathrm{~mm}$ distance between the material surface and light guide tip of the device, simulating the clinical restorative procedure. An important aspect, often ignored in previous studies, is where the light tip of the curing unit is placed in relation to the top surface of the material. When it is placed directly against the material, higher levels of energy would be delivered to top, and possible subsequently to the bottom surface. Alshali et al (2013) ${ }^{13}$, delivered a lower total energy to the top surface than was recommended by the manufacturers, placing the LCU at a distance from the surface. This would result in less total energy delivered to top surface which in turn may affect the curing of the material; not appropriate to judge the material as failed to be adequately cured. The total 
energy recommended by the manufacturers of Tetric EvoCeram ${ }^{\circledR}$ Bulk Fill ranged between 8 and 12 $\mathrm{J} / \mathrm{cm} 2$.Thus $12 \mathrm{~J} / \mathrm{cm} 2$ should have been more than sufficient to achieve adequate polymerization of the materials..$^{14}$

Vickers microhardness test was selected for this study because it is relatively a simple technique, very popular and reliable for obtaining the results. Additionally, it is considered by several authors as an indicator for the degree of polymerization of resin materials and used commonly as indirect method to evaluate degree of cure. Surface microhardness is considered as an indicative factor of the mechanical strength of a resin and correlates well to the material's rigidity ${ }^{15}$. The type of the resin composite had an effect on the VHN microhardness of resin composites.

At zero mm light curing distance for the top and bottom surfaces: increase the curing time did not increase the mean microhardness for all the tested materials, except the bottom surface of Tetric Evoceram, which showed an increase in the mean microhardness with the increase in the curing time. This is in agreement with several studies which did not find a correlation between microhardness number and longer polymerization time ${ }^{17,18,19}$, (Flury et al, 2012) ${ }^{17}$ measured the curing depth of bulk-fill composites using two methods of ISO4049 and microhardness testing after 10 and 20 seconds of curing and reported no significant difference in microhardness of bulk fill composites cured for 10 and $20 \mathrm{sec}-$ onds. In another study, no change in microhardness of bulk fill composites was observed by increasing the curing time from 30 to 40 seconds at $2-3.5 \mathrm{~mm}$ depths. However, an increase in microhardness following increased curing time has been reported by (Mousavinasab and Meyers, 2011) ${ }^{16} \mathrm{Also}$, (Mohammed and Ario , 2015) ${ }^{5}$ reported that, curing time positively affects the polymerization properties of bulk-fills. These finding may be attributed to the different types of initiators in the materials used in these studies and presence of two initiators and adequate polymerization of Tetric $\mathrm{N}$-Ceram which were used ${ }^{20}$.

Curing time affects the top/bottom microhardness ratio. All materials tested exceed the lowest required top to bottom ratio for any material which must exceed $80 \% .^{2} \mathrm{Admira}$ Fusion $\mathrm{x}$-tra and Filtek ${ }^{\mathrm{TM}}$ bulk-fill showed the highest top to bottom ratio that may be related to Ormocer-ceramic based composite and presence of zirconia fillers in Filtek ${ }^{\mathrm{TM}}$ bulkfill while Tetric EvoCeram ${ }^{\circledR}$ showed the lowest top to bottom ratio. This may be due to the effect of shades of the RBCs since this may influence the results. There were different shade classifications between manufacturers and some materials were only available in one shade, a universal shade. An effort was made to match the study shade to A2, whenever an appropriate material was available from the manufacturer, to avoid extra-white or extra-dark shades and also because this was probably the most commonly shades used in clinical dental practice. ${ }^{14}$

\section{CONCLUSION}

Under the conditions of this study the following conclusions could be drawn, the increase in the light curing time increased the top to bottom microhardness of bulk-fill resin composite.

\section{REFERENCES}

1. Nagi SM, Moharam LM and Zaazou MH. Effect of resin thickness, and curing time on the micro-hardness of bulkfill resin composites. J Clin Exp Dent,2015;7: 600-604.

2. Moore BK, Platt JA, Borges G, Chu TG and Katsilieri I. Depth of cure of dental resin composites: ISO 4049 depth and microhardness of types of materials and shades. Operative dentistry, 2008;33: 408-412.

3. Malhotra N, Kundabala M: Light-curing considerations for resin-based composite materials: a review. Part I. CompendContinEduc Dent 2010; 31: 498-505.

4. Jaberi AZ, Ghasemi A, Vatandoust MT, Kalantar MM: Effect of Curing Time on Polymerization Rate of Bulk-Fill Composite Resins. 2016;34(4): 214-224. 
5. Mohammed A and Ario S. Resin-Based Composite and LCU-related Factors Affecting the Degree of Cure. A Literature Review: Part 1. Resin-Based Composites. Acta Medica Marisiensis,2015;61: 153-157.

6. Yousef MK, Reem A and Ajaj A. Effect of Different LightCuring Units on Microhardness of Different Bulk Fill Materials. Life Science Journal,2015;12:24-30.

7. Ciccone-Nogueira JC, Borsatto MC, Souza-Zaron WCd, Ramos RP and Palma-Dibb RG. Microhardness of composite resins at different depths varying the post-irradiation time. Journal of Applied Oral Science,2007;15: 305-309.

8. Admira Fusion. (Voco).Scientific documentation Admira Fusion Xtra Bulk Fill,2016:15-17.

9. Guo G, Fan Y, Zhang J-F, Hagan JL and Xu X. Novel dental composites reinforced with zirconia-silica ceramic nanofibers. Dental Materials,2012;28: 360-368

10. BucutaS and Ilie N.Light transmittance and micro-mechanical properties of bulk fill vs. conventional resin based composites. Clinical oral investigations, 2014;18:1991-2000.

11. Ilie N, KeßlerA and Durner J. Influence of various irradiation processes on the mechanical properties and polymerisation kinetics of bulk-fill resin based composites. Journal of dentistry,2013;41: 695-7029-Shalan LA, Thiab SH: The Effect of Different Light Cure Systems on Microhardness of Bulk Fill Composite Materials. Journal of Baghdad Collegeof Dentistry 2017; 29: 13-20.

12. Chinelatti MA, Chimello DT, Ramos RP and Palma-Dibb RG. Evaluation of the surface hardness of composite resins before and after polishing at different times. Journalof Applied Oral Science,2006;14: 188-192.

13. Alshali RZ, Silikas N and Satterthwaite JD. Degree of con- version of bulk-fill compared to conventional resin-composites at two time intervals. Dental Materials,2013;29: 213-217.

14. Aldossary Mohammed1, Roebuck Elizabeth M1 and Santini Ario. Bulk Fill Resin Composite Materials Cured with Single-Peak versus Dual-Peak led light curing units. Acta Medica Marisiensis,2016;62:5-14..

15. Marghalani HY. Post-irradiation Vickers microhardness development of novel resin composites. Materials Research,2010;13: 81-87.

16. Mousavinasab SM and Meyers I. Comparison of depth of cure, hardness and heat generation of LED and high intensity QTH light sources. European journal of dentistry,2011;5: 299304-..

17. Flury S, Hayoz S, Peutzfeldt A, Hüsler J and Lussi A. Depth of cure of resin composites: is the ISO 4049 method suitable for bulk fill materials? Dental materials,2012;28: 521-528.

18. Okte Z, Villalta P, Garcia-Godoy F, Garcia-Godoy F and Murray P. Effect of curing time and light curing systems on the surface hardness of compomers. operative dentistry university of washington,2005;30: 540-545.

19. Catelan A, Pollard T, Bedran-Russo A, Santos Pd, Ambrosano $G$ and Aguiar F.Light-curing time and aging effects on the nanomechanical properties of methacrylateand silorane-based restorations.Operative dentistry,2014;39: 389-397.

20. Moszner N, Fischer UK, Ganster B, Liska R and Rheinberger $\mathrm{V}$. Benzoyl germanium derivatives as novel visible light photoinitiators for dental materials. Dental Materials,2008;2:901-907.. 